\title{
Happy New Year to all our readers? - and never was this more heartfelt or more significant
}

I really do hope that 2007 proves to be a better year for dentistry than 2006 was. Writers on the subject of Change Management often say that "Change hurts" and more profoundly that "Big change hurts a lot!" Having had nearly sixty years of working with a largely predictable, if chronically underfunded, National Health Service, general dental practitioners must now realise that the government means business. A long time ago, Sir Kenneth Bloomfield declared that "No change is not an option". But little did we know that the fruit of his review of NHS general practice dentistry would take fifteen years to ripen into something called nGDS.

For the government, the new contract may be seen as a master stroke. But the rest of us realise that this was nothing to do with patients, it was nothing to do with health and it most certainly was nothing to do with dentists. The new contract is about cost control and driving down market rates - it is a contract written by a finance professional, not by someone with an interest in health care. It has fundamentally failed in the stated intention of taking dentists off the treadmill and of providing an environment that encourages preventative dentistry. Having gone to the trouble of commissioning a range of possible options under PDS pilots it is a great shame and a missed opportunity that the government then went on to disregard them all and introduce something completely different. Given that many of the pilots seemed to be delivering on the stated aims, one has to wonder why?

Central government has also removed itself from the nasty business of accountability. It charged PCTs and LHBs with the responsibility of commissioning. They could do this any way they liked - as long as their contracts contained the compulsory 150 pages from the regulations. They were given a budget to do it (minus the expected patient contributions!) which supposedly reflected previous levels of consumption. Just to make life interesting for the people who had never had to do this before, they were, at the same time, told that they also were to be re-organised. I just wish I could believe that this was a conspiracy - it would be something worthy of a James Bond villain. Regrettably, I think not. I think the timing of the changes was purely shambolic coincidence.

But the consequences have been dire: the precipitous introduction of the new contract; the misunderstandings; the misinterpretations; ill-judged departures from the NHS; ill-judged remaining within the NHS; incomplete rules and un-thoughtout consequences.
So where does this leave us as we anticipate the contract's first anniversary? Well as dentists do, many are getting on with it. They are getting on with it in the belief that it will all be sorted out around them. Others are struggling, have struggled. In some areas there have been terrible fights over interpretation, over inaccurate values, over onerous terms and conditions. Progressively some of the difficulties are resolved - but the resolution is incomplete, and new themes continue to emerge. The fragmentation of commissioning makes it very difficult to gain any sense of consistency of approach. Local commissioning means doing it differently in different places - it means that local managers are accountable for both a service and a budget. It means that the pressure is only likely to increase.

Much of this leader has focused on the "other side" and that is quite deliberate. If dentists are to survive and prosper and have that happy new year that I wished, we need to take control of our future. To do so, we first need to understand what our options are. Signally, we must understand that the NHS has changed fundamentally and for ever.

The BDA has fought, and will continue to fight, over the legality of the new contract. Most importantly we will fight on behalf of individual members who have been wronged by inappropriate behaviour or unfair treatment. But whatever the outcomes, we must all realise that the future is going to be very different to the past. Dentists in general practice can no longer rely on a consistent, predictable right to practise what they want where they want. They must understand their own expectations and what their practices cost to run. They must get a clear understanding of what is on offer locally, both from the NHS commissioners and from the private market. In assessing these things they must also understand what they are committing to (there is a lot in those compulsory 150 pages that is yet to be brought to bear). When they have done all of this they need to decide on the best route for their practices and their careers.

The long relationship of dependency on the NHS is officially over. Dentists must now take control of their businesses in a business-like way. By taking some time out to make their practices viable and sustainable, they will then be able to get back to doing what they do best - caring for patients.

Peter Ward,

Chief Executive, BDA doi: $10.1038 /$ bdj.2007.43 